\section{KẾT LUẬN}

Tỉ lệ cạn kiêt cảm xúc mức cao chiếm $72,12 \%$; tỉ lệ tính tiêu cực mức cao chiếm $78,77 \%$; tỉ lệ hiệu quả cá nhân mức cao chiếm $67,26 \%$. Khi đánh giá kiệt sức chung, kết quả cho thây tỉ lệ có kiệt sức chung là 75,22\%.

Kết quả nghiên cứu cho thấy cân có một số biện pháp can thiệp như phân bố lịch trực đêm, tăng ca và trực cuối tuân hợp lý để tránh tình trạng một bác sĩ hay điều dưỡng phải trực ngoài giờ quá nhiêu, nâng cao sức khỏe thể chất và tinh thân của nhân viên y tế để đáp ứng với nhu câu của ngành, nghê.

\section{TÀI LIÊU THAM KHẢO}

1. Reith, P. T. Burnout in United States Healthcare Professionals: A Narrative Review. Cureus. 2018;10(12):e3681-e.

2. Rotenstein, S. L, Torre, M., Ramos, A. M, et al. Prevalence of Burnout Among Physicians: A Systematic Review. Jama. 2018;320(11):1131-50.

3. Nguyen, T. HT, Kitaoka, K., Sukigara, M., et al. Burnout Study of Clinical Nurses in Vietnam:
Development of Job Burnout Model Based on Leiter and Maslach's Theory. Asian Nursing Research. 2018;12(1):42-9.

4. Shanafelt, D. T, Balch, M. C, Bechamps, G., et al. Burnout and medical errors among American surgeons. Annals of surgery. 2010;251(6):995-1000.

5. Balch, M. C, Oreskovich, R. M, Dyrbye, N. L, et al. Personal consequences of malpractice lawsuits on American surgeons. Journal of the American College of Surgeons. 2011;213(5):657-67.

6. Welp, A., Meier, L. L, Manser, T. Emotional exhaustion and workload predict clinician-rated and objective patient safety. Frontiers in psychology. 2014;5:1573.

7. Shanafelt, D. T, Dyrbye, N. L, West, P. C, et al. Potential Impact of Burnout on the US Physician Workforce. Mayo Clinic proceedings. 2016;91(11):1667-8.

8. Li, H., Zuo, M., Gelb, W. A, et al. Chinese Anesthesiologists Have High Burnout and Low Job Satisfaction: A Cross-Sectional Survey. Anesthesia and analgesia. 2018;126(3):1004-12.

9. Asai, M., Morita, T., Akechi, T., et al. Burnout and psychiatric morbidity among physicians engaged in end-of-life care for cancer patients: a cross-sectional nationwide survey in Japan. Psycho-oncology. 2007;16(5):421-8.

\title{
ĐÁNH GIÁ ẢNH HƯởNG TRÊN TUẦN HOÀN, HÔ HẤP VÀ TÁC DỤNG KHÔNG MONG MUỐN CỦA PHƯƠNG PHÁP GIẢM ĐAU ĐƯờNG NGOÀI MÀNG CỨNG NGỰC DO BỆNH NHÂN TỰ ĐIỀU KHIỂN BẰNG ROPIVACAIN KẾT HợP VỚI FENTANYL SẢU MỔ MỞ VÙNG BỤNG
}

\section{TÓM TẮT}

Mục tiêu: Đánh giá ảnh hưởng trên tuân hoàn, hô hấp và tác dụng không mong muốn của phương pháp giảm đau ngoài màng cứng ngực do bệnh nhân tự điều khiển bằng ropivacain kết hợp với fentanyl sau mổ mở vùng bụng. Phương pháp nghiên cứu: Thử nghiệm lậm sàng ngẫu nhiên có so sánh trên 03 nhóm, mỗi nhóm bao gồm 35 bệnh nhân được chỉ định phẫu thuật ổ bụng mở. Hỗn hợp thuốc sử dụng giảm đau sau mổ là fentanyl $2 \mathrm{mcg} / \mathrm{ml}$ kết hợp lần lượt với ropivacaine $0,1 \%$ ở nhóm I, ropivacaine $0,125 \%$ ở nhóm II và ropivacaine $0,2 \%$ ở nhóm III. Đánh giá ảnh hưởng trên tuần hoàn, hô hấp và các tác dụng không mong muốn xuất hiện ở người bệnh trong quá trình làm giảm đau. Kết quả: Tân số tim của người bệnh giảm rõ rệt trong 15 phút đầu sau mổ ở cả 3

*Học viện Quân y

**Bệnh viện Trung ương Quân đội 108

Chịu trách nhiệm chính: Trần Hoài Nam

Email: namb5v103@gmail.com

Ngày nhận bài: 2.3.2021

Ngày phản biện khoa học: 22.4.2021

Ngày duyệt bài: 4.5.2021
Trần Hoài Nam*, Trần Đắc Tiệp*, Nguyễn Minh Lý**, Hoàng Văn Chương*

nhóm, và duy trì ổn định từ thời điểm 30 ph trở đi. Trung bình tần số thở của các bênh nhân trong nghiên cứu giảm từ 18,3 \pm 14 xuống 16,3 \pm 0,9 (lần/phút). Không có người bệnh nào gặp tình trạng $\mathrm{SpO} 2$ dưới 95\%. Thời gian trung tiện trung bình của người bệnh dưới 40 giờ và thời gian ngồi dậy trung bình dưới 20 giờ ở cả 3 nhóm. Các tác dụng không mong muốn gặp phải là nôn, buồn nôn và đau đầu với tỷ lệ thấp $<5 \%$. Không có trường hợp nào bị tụt catheter, tụt huyết áp, ngứa hoặc run. Kết luận: Các chỉ số tuần hoàn, hô hẩp của người bệnh ổn định trong giới hạn bình thường, các tác dụng không mong muốn gặp với tỷ lệ thấp ở cả 3 nhóm.

Tư khóa: ropivacain,fentanyl, giảm đau ngoài màng cứng ngực, phẫu thuâtt ổ bụng mở.

Công trình được thực hiện tại khoa Gây mê- Bệnh viện Quân y 103 - Học viện Quẩn y từ tháng 04/2015 đển tháng 07/2017.

\section{SUMMARY \\ EVALUATION OF CIRCULATORY, RESPIRATORY \\ EFFECTS AND OTHER ADVERSE EFFECTS OF \\ PATIENT-CONTROLLED THORACIC EPIDURAL ANALGESIA USING COMBINATION OF}




\section{ROPIVACAINE AND FENTANYL FOR PATIENTS UNDERGOING OPEN ABDOMINAL SUGERY}

Objectives: To evaluate the side effects of postoperative patient-controlled epidural analgesia using the combination of ropivacaine and fentanyl for open abdominal surgery. Methods: A randomized comparative clinical trial was performed on 3 groups of patients, each of which contained 35 patients with indication for open abdominal surgery. The medications applied for postoperative analgesia were made up of fentanyl $2 \mathrm{mcg} / \mathrm{ml}$ combined with ropivacaine $0,1 \%$ in group $\mathrm{I}$, ropivacaine $0,125 \%$ in group II and ropivacaine $0,2 \%$ in group III. The adverse effects of postoperative analgesia within 72 hours after surgery were documented. Results: The heart rate of patients in both the 3 groups considerably reduced within the first $15 \mathrm{~min}$ after surgery, but then remained stable from the thirteenth minute and then. The average respiratory rate of patients in the study diminished from $18,3 \pm 14$ to $16,3 \pm 0,9$ (cycle/min). No patient suffered from oxygen desaturation with $\mathrm{SpO} 2$ of lower than 95\%. In both three groups, the average time until postoperative fart was less than 40 hours, and the average time of the ability for the postoperative sitting position was less than 20 hours. Side effects were headache, nausea, and vomiting with low proportion $(<5 \%)$ There were no patients experiencing epidural catheter dislodgement, hypotension, pruritus, or shivering. Conclusion: The circulatory and respiratory parameters of all patients fluctuated within normal ranges, thereby substantially ameliorating the incidence of adverse effects.

Keywords: ropivacaine, fentanyl, thoracic epidural anesthesia, open-abdominal surgery

\section{I. ĐĂT VẤN ĐỀ}

Gây tê ngoài màng cứng (NMC) ngực là một trong những phương pháp gây mê hiệu quả giảm đau tốt nhất, thường được lựa chọn để giảm đau cho các phẫu thuật lớn và có mức độ đau nhiều như phẫu thuật mở vùng bụng. Trong nhiều năm gân đây, việc phẫu thuật mở vùng bụng dưới gây mê nội khí quản thường kết hợp với gây tê ngoài màng cứng để giảm đau sau mổ. Việc kết hợp này mang lại nhiều hiệu quả trong việc giảm đau sau phẫu thuật bụng và ít tác dụng phụ [9]. Ropivacain là một loại thuốc được sử dụng phổ biến trong việc gây tê ngoài màng cứng, ít độc hơn và tao ra hiệu ứng tương tự như các thuốc gây tê khác thông qua sự ức chế thuận nghịch của dòng ion natri trong các sợi thần kinh [10]. Tuy nhiên, kỹ thuật gây tê ngoài màng cứng còn có một vài tác dụng phụ có thể xảy ra, đặc biệt ở các phẫu thuật có nhiều rủi ro và mức độ đau nhiêu. Chính vì vậy chúng tôi thực hiện nghiên cứu nhằm: Đánh giá ảnh hưởng trên tuần hoàn, hô hấp và tác dụng không mong muốn của phương pháp giảm đau đường ngoài màng cứng bằng ropivacain kêtt hợp với fentanyl sau mô mở vùng bụng do bệnh nhân tự điều khiên.

\section{II. ĐỐI TƯỢNG VÀ PHƯƠNG PHÁP NGHIÊN CỨU}

1. Đối tượng nghiên cứu: 105 trường hợp có chỉ định phầu thuật ổ bụng mở được phân chia ngẫu nhiên thành 03 nhóm (nhóm I: $35 \mathrm{BN}$ dùng ropivacain $0,1 \%$; nhóm 2 : $35 \mathrm{BN}$ dùng ropivacain 0,125\%; nhóm 3: $35 \mathrm{BN}$ dùng ropivacain $0,2 \%$; ơ mỗi nhóm đều kết hợp với fentanyl $2 \mathrm{mcg} / \mathrm{ml}$ ) tại Bệnh viện 103 trong thời gian từ tháng 04 năm 2015 đến tháng 07 năm 2017.

Tiêu chuẩn lựa chọn và loại trừ: lựa chọn những bệnh nhẩn đồng ý thực hiện kỹ thuật, không có chống chỉ định với kỹ thuật và không dị ứng với thuốc tê; có tình trạng tâm thần kinh bình thường; loại trừ những bệnh nhân có biến chứng về phẩu thuật và/hoặc biển chứng về gây mê.

2. Quy trình nghiên cứu. Bệnh nhân được khám, chuẩn bị mổ thường quy, được giải thích kỹ và đồng ý thực hiện kỹ thuật, được hướng dẫn cách sử dụng thước đo VAS. Khởi mê bằng propofol $2 \mathrm{mg} / \mathrm{kg}$, fentanyl $2 \mathrm{mcg} / \mathrm{kg}$, rocuronium $0,6 \mathrm{mg} / \mathrm{kg}$ (tiêm tĩnh mạch). Duy trì mê bằng servofluran (2-3\%), thuốc giãn cơ rocuronium, giảm đau trong mổ bằng fentanyl ngắt quãng (không sử dụng giảm đau đường ngoài màng cứng). Ngừng thuốc mê khi bắt đầu khâu đóng da. Kết thúc phẫu thuật, bệnh nhân được rút ống NKQ khi đủ tiêu chuẩn.

Tiến hành giảm đau sau mổ khi mạch, huyết áp, $\mathrm{SpO} 2$ ổn định và điểm VAS $\geq 4$. Nếu VAS $<4$ thì theo dõi và đánh giá lại sau mỗi 15 phút. Liều đầu tính theo chiều cao của bệnh nhân $(\mathrm{cm})$ theo công thức sau: thể tích $(\mathrm{ml})=$ [chiều cao $(\mathrm{cm})-100] / 10$. Các thông số máy được cài đặt như sau: mỗi lần bấm (bolus) $3 \mathrm{ml}$, thời gian khóa 10 phút, liều duy trì $3 \mathrm{ml} / \mathrm{giờ}$, tổng liều giới hạn trong 12 giờ là $30 \mathrm{ml}$. Nếu điểm $V A S \geq 4$ sau 3 lần bấm PCA thì tiêm tĩnh mạch chậm ketogesic $30 \mathrm{mg}$ (đường tĩnh mạch), nhắc lại sau 4 giờ, liêu tối đa trong 24 giờ là 90 mg.

Các chỉ tiêu đánh giá bao gồm: đặc điểm chung như tuổi, giới tính, chiều cao, cân nặng, BMI; các thay đổi về tuần hoàn như tần số tim, huyết áp trung bình tại các thời điểm; các thay đổi về hô hấp như thay đổi tần số thở, $\mathrm{SpO}_{2}$ tại các thời điểm; tỷ lệ gặp các tác dụng không mong muốn như buồn nổn, nôn và đau đầu .

Các chỉ tiêu được ghi lại tại các thời điểm sau: $\mathrm{H}_{0}$ (trước tiêm thuốc); $\mathrm{H}_{0,25}$ (sau tiêm 15 phút); $\mathrm{H}_{0,5}$ (sau tiêm 30 phút); $\mathrm{H}_{1}$ (sau tiêm 1 giờ); $\mathrm{H}_{2}$ (sau tiêm 2 giờ); ); $\mathrm{H}_{4}$ (sau tiêm 4 giờ); ); H8 (sau tiêm 8 giờ); ); $\mathrm{H}_{16}$ (sau tiêm 16 giờ);); 
$\mathrm{H}_{32}$ (sau tiêm 32 giờ);); $\mathrm{H}_{48}$ (sau tiêm 48 giờ); $\mathrm{H}_{72}$ (sau tiêm 72 giờ).

Số liệu được xử lý bằng phần mềm Stata.

\section{KẾT QUẢ NGHIÊN CỨU VÀ BÀN LUÂN 1. Đặc điểm chung}

Bảng 1. Đặc điểm chung bệnh nhân

\begin{tabular}{|c|c|c|c|c|c|}
\hline \multicolumn{2}{|c|}{ Phân bố Nhóm } & $\begin{array}{l}\text { Nhóm I } \\
(n=35)\end{array}$ & $\begin{array}{l}\text { Nhóm II } \\
(n=35)\end{array}$ & $\begin{array}{l}\text { Nhóm III } \\
(n=35)\end{array}$ & $\mathbf{p}$ \\
\hline \multirow{2}{*}{ Giới tính (\%) } & Nam & 54,3 & 48,6 & 68,6 & \multirow{2}{*}{$>0,05$} \\
\hline & Nữ & 45,7 & 51,4 & 31,4 & \\
\hline \multirow{2}{*}{ Tuổi (năm) } & ${ }^{x} \pm S D$ & $56,7 \pm 13,4$ & $62,2 \pm 9,8$ & $58,2 \pm 12,6$ & \multirow{2}{*}{$>0,05$} \\
\hline & Min - Max & $24-88$ & $50-85$ & $28-81$ & \\
\hline \multirow{2}{*}{$\begin{array}{l}\text { Chiêu cao } \\
(\mathrm{cm})\end{array}$} & $\bar{x} \pm \mathrm{SD}$ & $156,6 \pm 7,8$ & $158,2 \pm 7,8$ & $155,5 \pm 8,2$ & \multirow{2}{*}{$>0,05$} \\
\hline & Min - Max & $143-171$ & $145-171$ & $144-170$ & \\
\hline \multirow{2}{*}{$\begin{array}{c}\text { Cân nặng } \\
(\mathrm{kg})\end{array}$} & ${ }^{x} \pm$ SD & $48,7 \pm 8,1$ & $49,6 \pm 7,3$ & $50,3 \pm 10,2$ & \multirow{2}{*}{$>0,05$} \\
\hline & Min - Max & $35-68,5$ & $36,2-65,6$ & $37,8-79,1$ & \\
\hline \multirow{2}{*}{$\begin{array}{c}\text { BMI } \\
\left(\mathrm{kg} / \mathrm{m}^{2}\right)\end{array}$} & $\bar{x} \pm S D$ & $19,8 \pm 2,5$ & $19,8 \pm 2,3$ & $20,8 \pm 3,7$ & \multirow{2}{*}{$>0,05$} \\
\hline & Min - Max & $14,2-23,7$ & $13,8-24,3$ & $16,2-32,5$ & \\
\hline
\end{tabular}

Kết quả nghiên cứu cho thấy sự khác biệt về tuối, cân nặng, chiều cao, BMI giữa các nhóm nghiên cứu không có ý nghĩa thống kê với $p>0,05$.

\section{Các chỉ số theo dõi}

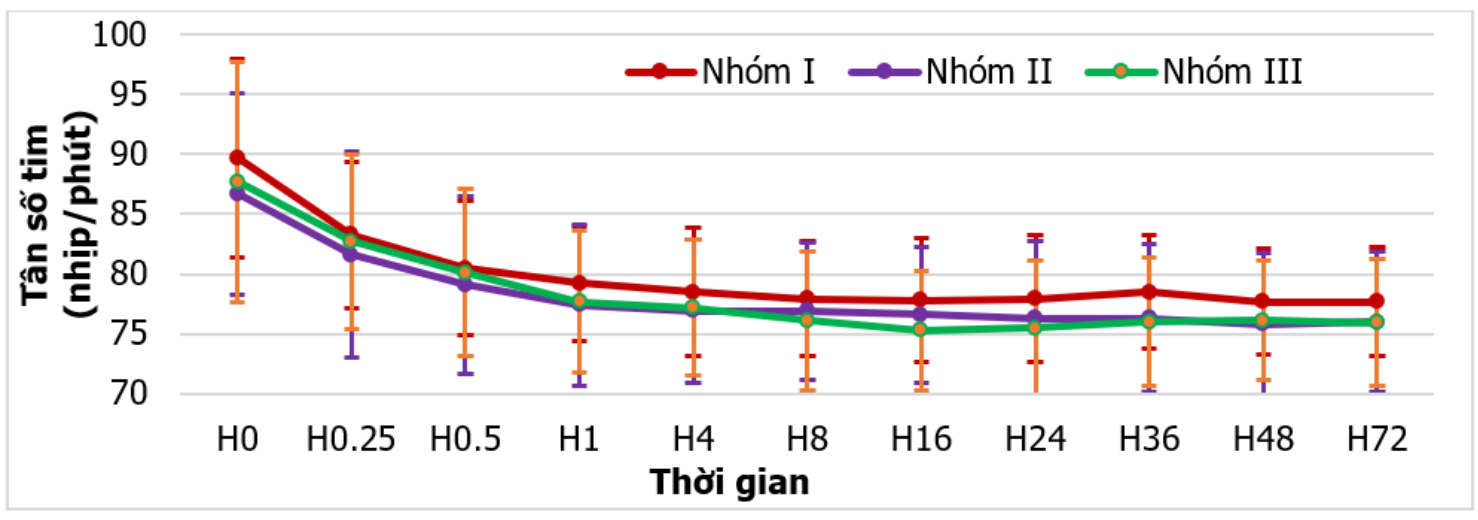

Biểu đồ 1. Biểu đồ thay đổi tân số tim ở các thời điểm

Sự thay đổi tần số tim trước tiêm và 72 giở sau tiêm không thay đổi nhiều ở cả ba nhóm. Mạch ở nhóm I cao hơn mạch ở hai nhóm còn lại, tuy nhiên sự khác biệt này không có ý nghĩa thống kê $(p>0,05)$.

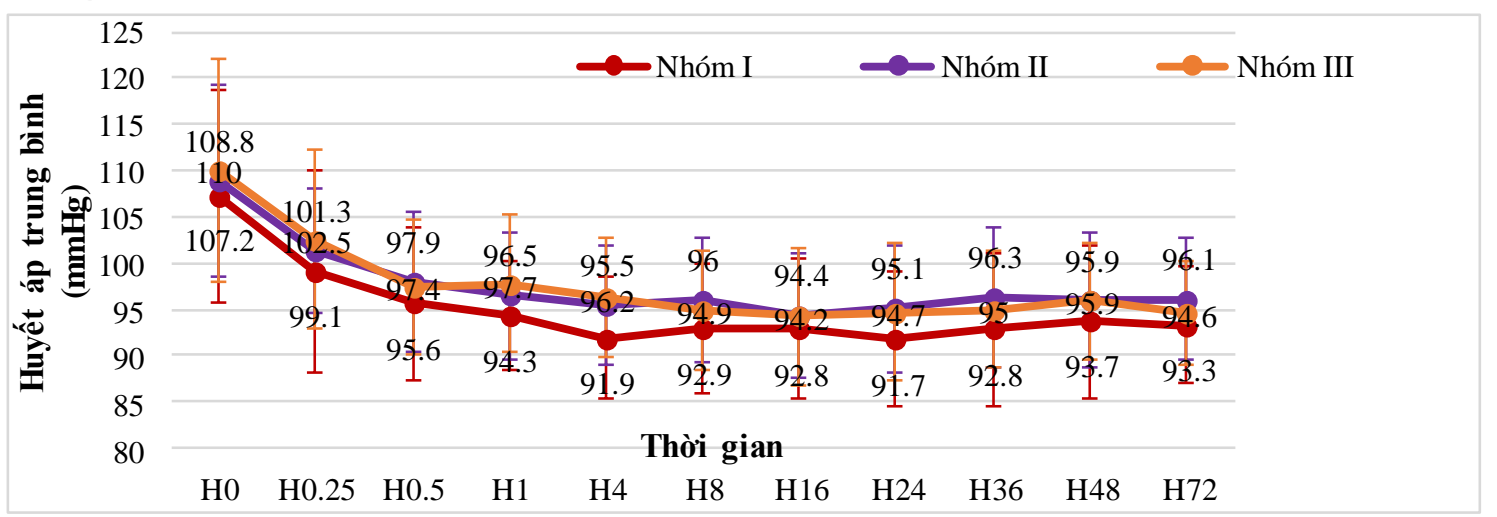

Biểu đồ 2. Thay đổi huyết áp trung bình ở các thời điểm

Huyết áp trung bình thay đổi theo thời điểm ở các nhóm, cao nhất tại thời điểm trước khi tiêm và giảm dần đến 72 giờ sau tiêm. Nhìn chung huyết áp trung bình của nhóm I thấp hơn so với hai nhóm còn lại. Và sự khác biệt này chỉ có ý nghĩa thống kê tại thời điểm 4 giờ sau tiêm $(\mathbf{p}<0,05)$. 


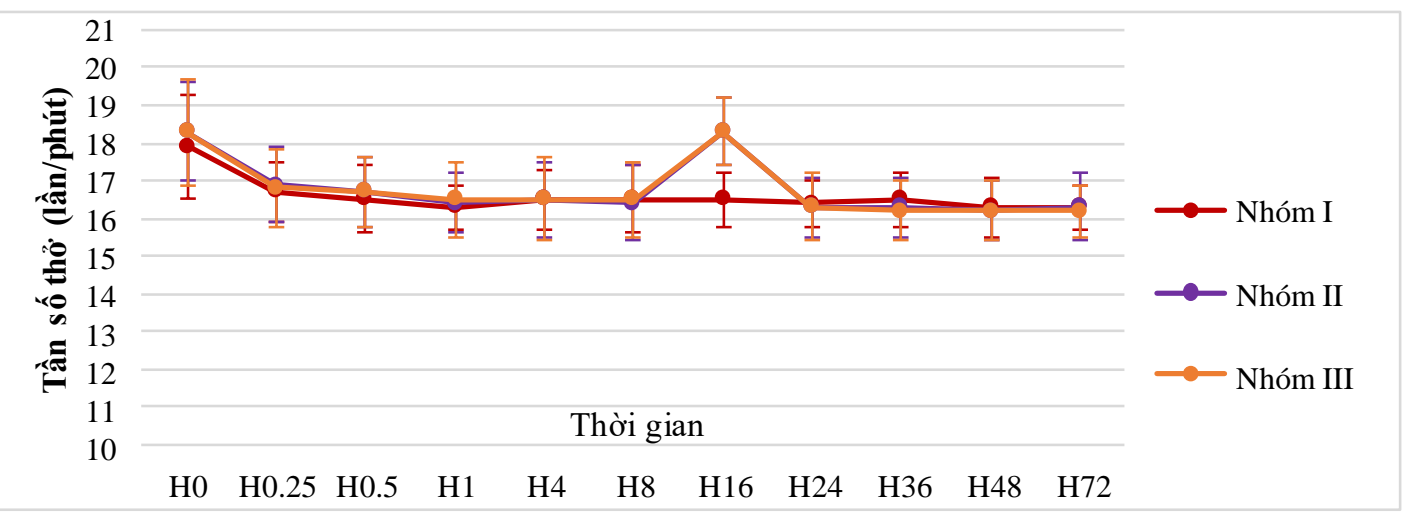

Biểu đồ 3. Biểu đồ thay đổi tần số thở ở các thời điểm

Tần số thở của ba nhóm trước tiêm và sau tiêm 72 giờ thay đổi không đáng kể. Sự khác biệt về tần số thở giữa ba nhóm tại các thời điểm đều không có ý nghĩa thông kê $(p>0,05)$.

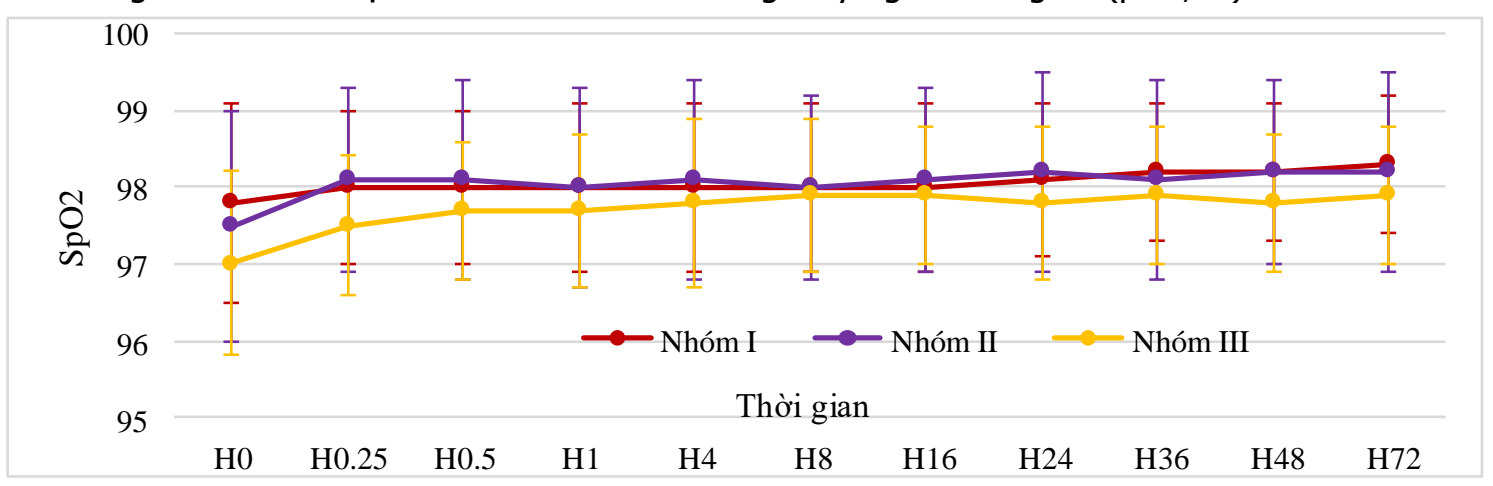

Biểu đồ 4. Biểu đồ thay đổi SpO ở các thời điểm

Độ bão hòa oxy mao mạch tại hầu hết các thời điểm đều tương đương ở cả ba nhóm $(p>0,05)$, không có bệnh nhân nào gặp tình trạng $\mathrm{SpO}_{2}$ dưới $95 \%$.

3. Các chỉ tiêu theo dối biến chứng và tác dụng không mong muốn

Bảng 2. Tác dụng không mong muốn

\begin{tabular}{|c|c|c|c|c|}
\hline Biến chứng Nhóm & $\begin{array}{c}\text { Nhóm I } \\
(\mathbf{n = 3 5 )}\end{array}$ & $\begin{array}{c}\text { Nhóm II } \\
(\mathbf{n = 3 5 )}\end{array}$ & $\begin{array}{c}\text { Nhóm III } \\
(\mathbf{n = 3 5 )}\end{array}$ & $\mathbf{p}$ \\
\hline Buồn nôn, nôn & $5(14,3 \%)$ & $4(11,4 \%)$ & $4(11,4 \%)$ & $>0,05$ \\
\hline Đau đâu & $2(5,7 \%)$ & $3(8,6 \%)$ & $2(5,7 \%)$ & $>0,05$ \\
\hline
\end{tabular}

Biến chứng buồn nôn găp ở cả 3 nhóm với tỷ lê thấp (từ 11,4 đến 14,3\%). Số lượng bênh nhân đau đầu là không đáng kể ở cả ba nhóm. Nghiên cứu không ghi nhận bệnh nhân nào có các tác dụng không mong muốn khác như: tụt huyết áp, rét run, ngứa, ức chế vận động,...

\section{BÀN LUẬN}

Các kết quả về thông tin chung giữa các nhóm nghiên cứu cho thấy sự đồng nhất về đặc điểm các bệnh nhân tham gia, giúp nghiên cứu loại bỏ các yếu tố gây nhiễu ảnh hưởng tới kết quả đạt được.

Kết quả nghiên cứu từ biểu đồ 1 cho thây tần số tim của người bệnh giảm rõ rệt trong 15 phút đâu sau mổ ở cả 3 nhóm, và duy trì ổn định từ thời điểm 30ph trở đi. Tần số tim ở nhóm I cao hơn ở hai nhóm còn lại, tuy nhiên sự khác biệt này không có ý nghĩa thống kê $(p>0,05)$. Sự giảm của tần số tim trong 15 phút đầu phù hợp với sự giảm của điểm VAS khi nghỉ trong thời gian này. Việc giảm đau tốt dẫn đến giảm nhịp tim, từ đó làm giảm thiểu các nguy cơ về tim mạch, đặc biệt là các đợt thiếu máu cơ tim kích hoạt bởi các cơn đau. Trong nghiên cứu này cũng không quan sát thấy sự khác biệt về nhịp tim giữa các nhóm trong nghiên cứu $(p>0,05)$. Nhìn chung gây tê ngoài màng cứng ngực ức chế chọn lọc đám rối tim $\mathrm{T} 1$ - T5, làm giảm trương lực giao cảm của các sợi phân bố cho cơ tim, các sợi này làm đẩy nhanh các biến đổi về mạch, từ đó làm giảm nguy cơ rối loạn nhịp tim sau mổ [4]. 
Biểu đồ 2 cho kết quả chỉ số huyết áp trung bình cho thấy huyết áp tương đối ổn định ở nhóm II, và nhóm III, ngược lại, ở nhóm I, chỉ số này có sự biến đổi với biên độ lớn hơn, dẫn đến có sự khác biệt ở các thời điểm H1, H4, H24 và H72. Điều này có thể lý giải là do hốn hợp với nông độ ropivacain $0,1 \%$ không có sự giảm đau ổn định bằng 2 nồng độ còn lại. Hạ huyết áp một phần do ức chế hoạt động hệ tim mạch, một phần do giãn các mạch máu ngoại vi [3].

Biểu đồ 3 đánh giá trung bình tần số thở của các bệnh nhân trong nghiên cứu giảm từ 18,3 \pm 14 xuống 16,3 \pm 0,9 (lân/phút). Trước khi được giảm đau, bệnh nhân thường thở nhanh, nông, nhịp thở không đều, bệnh nhân không dám thở do đau. Sau khi được giảm đau, bệnh nhân hoàn toàn có thể thở sâu, vì vậy biên độ thở của bệnh nhân tăng lên rõ rệt [7]. Trong nghiên cứu này, sự thay đổi về tần số thở sau khi có tác dụng giảm đau cho thấy việc theo dõi về hô hấp sau mổ ở những bệnh nhân giảm đau bằng gây tê $\mathrm{NMC}$ là cần thiết và cần phải theo dõi sát nhằm phát hiện sớm các tác dụng không mong muốn của phương pháp này.

Nghiên cứu của Patil SS. (2018) đã nhận định ropivacain kết hợp opioid như fentanyl ít ảnh hưởng tới độ bão hoà oxy hơn morphin [6]. Sự di chuyển vào khoang dưới nhện của catheter $\mathrm{NMC}$, quá trình truyền dịch liên tục còn làm gia tăng liên kết protein (a1-acid glycoprotein) và giảm độ thanh thải của thuốc là các yếu tố nguy cơ gây suy hô hấp. Một số yếu tố khác liên quan tới biến chứng hô hấp sau mổ như giãn cơ tồn dư, giãn nở của phổi kém, trào ngược...Tương tự với một số nghiên cứu trước đây, kết quả nghiên cứu của chúng tôi cho thấy tính an toàn và ổn định cao về bão hoà oxy qua phương pháp giảm đau sau phẫu thuật bằng catheter NMC [2].

Nghiên cứu của Jain R (2016) cũng cho kết quả tương tự khi không có bệnh nhân nào có biểu hiện nôn khi được giảm đau bằng ropivacain $0,1 \%$ kết hợp fentanyl [5]. Việc sử dụng ropivacain kết hợp fentanyl đã được nhiều nghiên cứu chứng minh là ít gây nôn, buồn nôn hơn morphin. Các thuốc ho morphin có thể được hấp thu vào dịch não tủy và máu đi lên kích thích trung tâm nôn ở sàn não thất, do đó nôn và buồn nôn thường gặp với morphin hơn là với fentanyl và các opioid khác [8].

Tình trạng đau đầu gặp với tỷ lệ thấp và tương đướng ở cả 3 nhóm, sự khác biệt này không có ý nghĩa với $p>0,05$. Kết quả này thấp hơn Sadhu R (2015) là 23,3\% [8], .Nghiên cứu của Nguyễn Đức Lam (2013) cho thấy khi vô tình chọc thủng màng nhện với kim gây tê ngoài màng cứng thì tỷ lệ đau đâu là 52,1\% [1].

\section{KẾT LUÂNN}

Qua nghiên cứu về hiệu quả giảm đau NMC ngực với hỗn hợp ropivacain nồng độ $1 \%$, $0,125 \%, 0,2 \%$ kết hợp với fentanyl $2 \mathrm{mcg} / \mathrm{ml}$ do bệnh tự điều khiển sau phẫu thuật mở ổ bụng, chúng tôi rút ra kết luận: Các chỉ số tuần hoàn, hô hấp của người bệnh đều thay đổi trong giới hạn bình thường, sự khác biệt giữa các nhóm về tác dụng không mong muổn (buồn nôn, nôn, đau đầu) không có ý nghĩa thống kê ( $p>0,05)$.

\section{TÀI LIÊU THAM KHẢO}

1. Ngưyễn Đức Lam (2013), Đánh giá hiệu quả của phương pháp gây tê tủy sống và gây tê tủy sống ngoài mang cứng phối hợp để mổ lây thai ở bệnh nhân tiên sản giật nặng, Luận án Tiến sỹ Y học, Đai học Y Hà Nối.

2. Trân Đức Thọ (2017), Nghiên cứu tác dụng giảm đau sau mổ bung trên của Levobupivacain phối hợp với Sufentanil hoặc Fentanyl hoặc Clonidin qua catheter ngoài màng cứng bệnh nhân tư điêu khiên, Luận án Tiến sĩ $Y$ học, Viện nghiển cứu Khoa học Y Dược Lâm sàng 108.

3. Clemente A., Carli F. (2008), "The physiological effects of thoracic epidural anesthesia and analgesia on the cardiovascular, respiratory and gastrointestinal systems", Minerva Anestesiol. 74(10), p. 549-63.

4. Hansdottir V., et al (2006), "Thoracic epidural versus intravenous patient-controlled analgesia after cardiac surgery: a randomized controlled trial on length of hospital stay and patient-perceived quality of recovery", Anesthesiology. 104(1), p. 142-51.

5. Jain Rashmi, Gupta Pushpalata, Jain Vinita (2016), "A comparison of ropivacaine with fentanyl to bupivacaine with fentanyl for post-operative patient controlled epidural analgesia in patients undergone lower abdominal cancer surgery", J IAIM. 3(7), p. 137-149.

6. Patil Shruti Shrikant, Kudalkar Amala G., Tendolkar Bharati A. (2018), "Comparison of continuous epidural infusion of $0.125 \%$ ropivacaine with $1 \mu \mathrm{g} / \mathrm{ml}$ fentanyl versus $0.125 \%$ bupivacaine with $1 \mu \mathrm{g} / \mathrm{ml}$ fentanyl for postoperative analgesia in major abdominal surgery", Journal of anaesthesiology, clinical pharmacology. 34(1), p. 29-34.

7. Scott N. B., et al (1996), "Continuous thoracic epidural analgesia versus combined spinal/thoracic epidural analgesia on pain, pulmonary function and the metabolic response following colonic resection". 40(6), p. 691-696.

8. Yvan Pouzeratte., Jean M. Delay., Georges Brunat. (2001), "Patient-Controlled Epidural Analgesia After Ábdominal Surgery: Ropivacaine Versus Bupivacaine", Anesth Analg. 93, p. 1587-1592.

9. Zafar N., et al (2010), "The evolution of analgesia in an 'accelerated' recovery programme for resectional laparoscopic colorectal surgery with anastomosis", Colorectal Dis. 12(2), p. 119-24. 